\title{
Periodismo, transición y cambio cultural
}

Por Faride Zerán

A minutos de haber cruzado el milenio la necesaria pregunta acerca del rol del periodismo en el cambio cultural y en la conformación de ciudadanía nos ubica en la frontera del país que soñamos y del país que queremos con aquel que hemos sido capaces de reconstruir luego de casi dos décadas de régimen militar.

Si el periodismo es el espejo en el cual se mira el más amplio espectro de una sociedad; si el periodismo es aquella disciplina en donde se confrontan los más diversos matices de una pluralidad sin límites; si estamos ante una profesión capaz de cumplir su rol fiscalizador, distante de todo poder, al servicio de las mayorías y a la vez aguafiestas de los vaivenes y devaneos de ellas, hoy, ya en el nuevo siglo y sintiendo tras nuestro el peso de una república que en su fulgor fue capaz de legarnos lo mejor del debate libre, lo más granado de las nuevas ideas, o lo más complejo de la reflexión intelectual, sin omitir el fragor de las confrontaciones odiosas pero verdaderas en tanto daban cuenta de un país real al menos en el periodismo versus el cambio cultural, debemos concluir que, a veces, la historia retrocede.

Porque en este siglo XXI, y en un balance que nos avergüenza, debemos decir que tenemos el periodismo ad hoc a una sociedad sesgada y con mordazas que, con desparpajo cambia de milenio como quien hace uso del zapping, el pequeño aparato sin historia y sin memoria que por arte de magia nos traslada a todos los mundos posibles, en un ejercicio sin contrapesos que nos deja en los bordes de la desidentidad.

Atrás han quedado los episodios que nos retrotraen a un país polémico, multifacético e iconoclasta con varios lujos a su haber: como el de una prensa fundacional libertaria a cargo de Fray Camilo Henríquez, en los albores de la República; como los decretos contra la censura y a favor del librepensamiento, de O'Higgins, o, para situarnos en los inicios del siglo pasado, léase el siglo 20, las proclamas libertarias del flamante candidato a la presidencia de la república escritas en un periódico llamado "Acción", "diario de purificación nacional", a través del cual el candidato de la Federación de Estudiantes de Chile, Vicente Huidobro, escribía, en 1925, su "Balance Patriótico", en el cual señalaba, entre algunos párrafos para la historia:

"...Frente a la antigua oligarquía chilena, que cometió muchos errores, pero que no se vendía, se levanta hoy una nueva aristocracia de la banca, sin patriotismo, que todo lo cotiza en pesos y para la cual la política vale tanto cuanto sonante pueda sacarse de ella. Ni la una ni la otra de estas dos aristocracias han producido grandes hombres, pero la primera, la de los apellidos vinosos no llegó nunca a la impudicia de los apellidos bancosos.

...Toda nuestra insignificancia se resuelve en una sola palabra: Falta de alma.... Crisis de hombres; Una nación no es una tienda, ni un presupuesto es una Biblia...Todo lo grande que se ha hecho en América y sobre todo en Chile, lo han hecho los jóvenes. Así es que pueden reírse de la juventud. Bolívar actuó a los veintinueve años. Carrera a los veintidos; o'higgins, a los treinta y uno, y Portales a los treinta y seis. Que se vayan los viejos y venga la juventud limpia y fuerte, con los ojos iluminados de entusiasmo y esperanza..."(1)

Huidobro tiene 32 años, y se levanta contra sus orígenes en una rebeldía propia de quien abrazará pocos años después el grito de Rimbaud con la consigna de que hay que ser modernista.

El Chile de esos años ya ha dado sus frutos más insignes: Pablo Neruda, Gabriela Mistral, Pablo de Rokha, Eduardo Anguita, Volodia Teitelboim, Humberto Díaz Casanueva, Angel Cruchaga, y otros tantos que se aprontan a cruzar el milenio. Ellos, de la mano de su talento, sembrarán vientos y cosecharán tempestades, como corresponde a los talantes disidentes. 
Es decir, los Gonzalo Rojas, Nicanor Parra, José Donoso, José Balmes, Violeta Parra, y tantos otros que cubrirán de gloria la República caminando contra la corriente.

Para todos ellos hubo prensa: adversa o afín, pero prensa, clandestina u oficial, pero prensa capaz de tender el puente de rosas o de púas. El Chile cultural tuvo debate gracias a sus órganos adversos y diversos que dieron cuenta de la riqueza de una nación.

$Y$ es que no puede haber balance complaciente en el contexto de una universidad como la nuestra que piensa a Chile. No lo puede haber si asumimos nuestro papel de conciencia crítica de la nación, o si hacemos nuestros los versos de Julio Barrenechea, quien dijo hace ya muchas décadas que: "si la Patria en un tiempo dormía, escuchando tu voz despertó, Tus murallas quedaban heridas, pero alzabas tu espíritu en flor".

\section{La deuda del periodismo}

En este sentido, hoy podemos decir que el periodismo chileno tiene una deuda con la sociedad, una deuda por acción y omisión, plasmadas en una década de silencios y complicidades que se traducen en la proyección de una sociedad homogénea, acrítica, sin debate, y a través de la cual emerge un sujeto popular asimilado a la figura del delincuente; un sujeto cultural reducido a la era del espectáculo; un sujeto intelectual percibido como denso y cuya palabra o aporte no sirve en tanto no puede ser banalizada.

Porque el país blanco, sin orígenes y memoria que emergió a comienzos de los noventa en la metáfora del iceberg con que Chile quiso ser representado en la Expo Sevilla, no fue una construcción casual. Los medios, los discursos oficiales, el decretado consenso o ley del silencio que surgió con el inicio de la transición democrática, postergando el necesario debate sobre nuestras diferencias propias de un país fragmentado por el dolor y el horror, omitía no sólo una parte esencial de su ser, mestizo, plural, diverso y con patrimonio y memoria cultural. También, la posibilidad de enjuiciar moralmente un pasado para que efectivamente el "nunca más" no fuera solo una consigna sino un legado para las próximas generaciones.

Los finales de los ochenta y la década de los noventa confirmaron que el iceberg era la metáfora de la simulación. La prensa independiente, aquella capaz de dar cuenta de los conflictos y debates más ricos de nuestra sociedad fue desapareciendo paulatinamente, mientras se perfilaba con fuerza la concentración de los medios escritos, a través de dos grandes conglomerados, El Mercurio y Copesa, y desde La Moneda se nos decía que era un tema de mercado.

Así, bajo la excusa del mercado desaparecieron los diarios "El Fortín Mapocho", "La Epoca", las revistas "Análisis", Cauce", "Hoy", "Pluma y Pincel", "Los Tiempos", "Página Abierta", "El Canelo", por nombrar algunas, y la diversidad, el debate plural, la riqueza de otras miradas quedó sepultada en un tema económico.

La agenda pública emanada de los órganos del poder político, empresarial, y militar nos reflejaba un país conservador, censurado, con miedo a la libertad.

El divorcio, el aborto, la diversidad sexual, los pueblos originarios, la violación de los derechos humanos, por citar algunos temas, fueron desplazados del debate, y la seguridad ciudadana, los índices económicos, el fútbol, y el show de mal gusto se impusieron en la vida cotidiana de los chilenos.

La modernidad era sinónimo de consumo, de celulares de palo, de chilenos agresivos que se transformaban en los fenicios de América. "Tigres de papel, cómo me río de los tigres de papel", exclamaba Donoso en la irritación del malestar de la cultura ante el exitismo de una sociedad complaciente. "No hay Chile contemporáneo sin una franqueza y un develamiento de cosas. Somos una mata de cardenales en el jardín, polvorienta y fea", reiteraba José Donoso, a la vez que puntualizaba: "Este Chile que está oculto y que es mentiroso es un Chile de otro tiempo, es el resabio del siglo pasado." 
Paralelamente a la desaparición de la prensa independiente, las radios y la televisión iniciaban un proceso de cambio de propiedad que, salvo excepciones, ratificaba el proceso de banalización y simulación, de la cual quedaban marginados el alma y el sentido más profundo del país real.

Tal vez, el Informe del PNUD (Programa de las Naciones Unidas para el Desarrollo), "Las paradojas de la modernización", se constituyó en la radiografía más severa de los noventa dando cuenta de las cifras del desencanto en un país escindido, desconfiado, lleno de temores y desinformado.

Los medios de comunicación y el periodismo con su explosión de escuelas a lo largo del país, más de treinta y cinco, formando profesionales para el mercado, o cesantes al servicio de la información como mercancía, despojados de su rol de servidores públicos hacia las mayorías y de defensores de las minorías, de seres comprometidos con los valores del humanismo, de las libertades, de la paz, de la justicia y de los principios democráticos, y anclados en conceptos claves como son el derecho a la información y a la libertad de expresión, completaban un contexto de crisis.

Porque los noventa en Chile se inician con un periodista exiliado: Francisco Martorell, autor del libro "Impunidad Diplomática", y culminan con una periodista asilada en Estados Unidos, Alejandra Matus, autora de "El libro negro de la justicia chilena". Entre medio, la censura cinematográfica, las leyes de desacato como el artículo 6 b de la Ley de Seguridad del Estado que sanciona con la cárcel la necesaria fiscalización que debe tener el periodismo sobre todos los poderes y sus autoridades.

Junto a ello, las normas restrictivas del Código Penal, las sanciones internacionales a Chile por la persistencia de leyes y normas que impiden la libertad de expresión, la existencia de una ley de prensa que, pese a los anuncios, duerme aún en el Congreso, y el silencio cómplice de todos los poderes, incluido el del Estado chileno, frente a su obligación de garantizar la primera de todas las libertades, la libertad de expresión.

¿Periodismo y cambio cultural? Buena alianza, sólo que para concretarla sin ambigüedades hace falta retomar el rol del periodismo y su tradición libertaria e independiente, culta e informada, de aporte al debate y a la reflexión, en el contexto de una sociedad tolerante que deja de temerle a la libertad, y que emerge desde los centros y márgenes con toda su riqueza, diversidad y pluralidad de voces.

¿Periodismo y cambio cultural? Buen reto, sólo que para ello es necesario derogar las leyes que establecen la censura, normar la peligrosa concentración de los medios, democratizar el avisaje a través de leyes que lo garanticen, y redemocratizar un país ávido de verdad y rico en su memoria y tradición cultural.

¿Periodismo y cambio cultural? Sí, pero cuando en este país la televisión pública se atreva a mostrar la creación de sus artistas, cuando veamos en la pantalla las imágenes de los documentales de Silvio Caiozzi, Patricio Guzmán, de Carmen Castillo, de Esteban Larraín, y de tantos otros cineastas cuyas obras son premiadas en el exterior pero desconocidas en su tierra.

¿Periodismo y cambio cultural?, cuando la ciudadanía asuma que la información es un derecho que debe ser garantizado como la vida, la educación o el trabajo.

\section{Periodismo y ciudadania}

Comunicación y ciudadanía nos remite en primer lugar a un principio elemental, cual es el derecho a la información veraz y oportuna de todo ciudadano y ciudadana, y el derecho a informar de manera libre y responsable de quienes ejercen la profesión de periodistas. 
Esto implica hacernos cargo de la situación de los medios en nuestro país en el marco de la libertad de expresión, de la libre circulación de las ideas, del derecho a la información, así como del rol de los profesionales de la prensa en cuanto su papel fiscalizador, crítico e independiente de los poderes.

Si para Umberto Eco, la función del cuarto poder es la de controlar y criticar a los otros tres poderes tradicionales, como lo expresa en su ensayo "Sobre la prensa", para el periodista argentino Horacio Verbitsky la información no es un privilegio de los periodistas sino un derecho de los pueblos, y la mejor contribución al afianzamiento de una cultura democrática reside en decir la verdad de los hechos.

Estas visiones coincidentes acerca del papel fiscalizador y crítico del periodismo en el marco de la libertad de expresión ensalzada como la primera de todas las libertades se estrellan con varios flagelos.

Uno, derivado de las leyes de la oferta y la demanda que transforma la noticia en una mercancía transable en el vasto mercado donde se esfuma la ética o la esencia misma del periodismo, y en el cual la única crítica bien vista al modelo neoliberal es la de los recursos perdidos en el sumidero de la corrupción que podrían aplicarse a paliar las penurias de la malnutrición, la ignorancia y la enfermedad.

"En la denuncia de los hechos de corrupción gubernativa sentencia Verbintsky la prensa demuestra hoy el valor que no tuvo cuando ocurrieron las peores violaciones a los derechos humanos. Esto hizo que la tensión natural entre la prensa y el poder político evolucionara hacia niveles de conflicto."

Sin embargo, concluye, su enfoque de la corrupción tiende a trivializar lo que se describe. "En todo el continente (la prensa) se ha especializado en el seguimiento de los políticos corruptos, pero se interesa menos en el poder económico que los corrompe y por la corrupción estructural del modelo".

La experiencia de la prensa chilena, es similar a la de argentina en tanto su silencio cómplice en los años de la dictadura. Como señala el Informe de la Comisión Verdad y Reconciliación, constituida a inicios de la transición por el entonces Presidente Patricio Aylwin: " La desinformación de la opinión pública por los medios de comunicación contribuyó sin duda a mantener las violaciones a los derechos humanos en el país ".

Sin embargo, ese pasado tiene matices desde inicios de los ochenta por el surgimiento de una prensa independiente del régimen militar que asumió con valentía el deber ético de entregar la verdad, no sin pagar los costos y peligros que ello implicaba.

En este marco, ya abordado, vale la pena detenerse en el episodio de las indemnizaciones denunciado ampliamente y que puso en el banquillo de los acusados no sólo a las empresas del Estado, sino a los funcionarios públicos y a los gobiernos de la Concertación.

¡Qué duda cabe que efectivamente hubo abusos de algunos, que merecidamente han sido sancionados!

De este capítulo que nos habla de la necesaria transparencia de toda sociedad democrática, sin embargo, surge una reflexión.

En los inicios de los noventa, la prensa independiente que denunció los escándalos financieros, las indemnizaciones millonarias y prácticamente el remate de las empresas del Estado en las postrimerías del régimen militar, fue acallada por el nuevo gobierno democrático en aras del consenso y de la paz social. 
Para nuestros gobernantes, la precariedad de la democracia no resistía en esos años la denuncia de corrupción.

A nombre de la política de los acuerdos, se hipotecaba el carácter fiscalizador de una prensa que sustentaba la autoridad moral para emprender el juicio ético a un régimen que además había engrosado sus arcas.

Sin ese debate y diez años después muchos pensaron que aún imperaba la impunidad del silencio y entonces, quizás, este triste capítulo no se habría producido

\section{Limitaciones a niveles incomparables}

Un diagnóstico de la organización Human Rights Watch(2)sostiene que en la actualidad la libertad de expresión e información está limitada en Chile hasta un nivel posiblemente incomparable con cualquier otra sociedad democrática del hemisferio occidental.

En un trabajo preparado por investigadores del Programa Interdisciplinario de Libertad de Expresión de la Escuela de Periodismo de la Universidad de Chile, "Dolores y sombras del periodismo chileno"(3), publicado en la revista Rocinante, se señala textualmente entre los indicadores regresivos "la desaparición de diarios y revistas que se distinguieron por su impulso antiautoritario; la consolidación, en la prensa escrita, del duopolio favorito del régimen militar formado por El Mercurio y Copesa; el predominio abrumador de medios ultraliberales en lo económico e integristas en lo moral, que de ninguna manera responden a la gama completa de ideas y tendencias del conjunto de la población."

En ese mismo informe escrito por los profesores Rafael Otano y Guillermo Sunkel, y por la ayudante Claudia Lagos, se enumeran los vicios y las lacras del ejercicio del periodismo, entre los que destacan la censura, la autocensura, así como la instalación de un periodismo denominado "políticamente correcto" que en su esencia implica la inhibición de la capacidad propositiva de los periodistas en las reuniones de pauta, a partir de temas evitados por inútiles, peligrosos o por generadores de conflicto.

"La inhibición de la capacidad de iniciativa señala el informe está asociada a la determinación que ejercen ciertas fuentes, especialmente influyentes, como el gobierno, organizaciones internacionales, poderes fácticos, en los temas de la pauta."

En este trabajo se destaca que la frustración acumulada a lo largo de la década por la falta de un periodismo más libre y plural, se encuentra asociada a la prevalencia de una debilitada cultura profesional de los periodistas.

Este panorama de la prensa chilena nos plantea como primer desafío del tercer milenio revertir dicho cuadro de silencios y omisiones que nos alejan definitivamente del rol crítico, independiente y fiscalizador que debe tener el periodismo en su contribución al fortalecimiento de una ciudadanía informada y consciente de sus derechos y deberes.

Pero, sin duda no constituye el único reto. Otro es lo que Eco denomina algo así como la televización de la prensa, aquella que es esclava de la televisión, que a fuerza de competir con ella eleva todo al sentido del espectáculo, la que es capaz de alargar lo que no es noticia y eliminar aquella que siéndolo sencillamente no vende, lo que junto a la pérdida de lectores la hace perder credibilidad6.

Según Ignacio Ramonet, en Estados Unidos el 55 por ciento de los ciudadanos estima que los medios de comunicación escritos publican informaciones con frecuencia inexactas. Para Ramonet, estamos en medio de la era de la sospecha, en tanto la información entra de lleno en la lógica del espectáculo en un fenómeno que se impone en la televisión pero de la cual no es ajena la prensa escrita7 
En relación con nuestra televisión, ejemplos al respecto sobran. Basta remitirse al libro de Guillermo Blanco sobre nuestros "tonticiarios", sumidos en la autocensura y en su falta de innovación, de jerarquización de los hechos, satirizados magistralmente por nuestro Premio Nacional de Periodismo, y que resulta una metáfora del malestar de amplios sectores de la ciudadanía con la televisión en general y, particularmente con el rol de la televisión pública especialmente en materia informativa(4).

Porque si el pluralismo se mide a ritmo de cronómetro en una sucesión de imágenes que dan cabida sólo a los partidos políticos, sean de gobierno o de oposición, dejando al margen una dimensión más amplia y rica de nuestra sociedad, obviando el debate, la reflexión, eludiendo los temas culturales y escapando de la entrega de opinión o de una perspectiva a veces necesaria para comprender los hechos, el malestar está más que justificado.

Más, cuando estamos hablando de una ciudadanía que en un contexto de superabundancia de información, paradojalmente tiene la certeza de que nunca había estado tan desinformada.

Para estimular un debate recurrente en nuestro medio, sobre el dominio de las redes de Internet que dejarían obsoleta la información de la prensa escrita, una provocación de Eco, contenida en su ensayo "Sobre la prensa", aquella que según él tiene una función fundamental no sólo para el crecimiento cívico de un país sino para el placer de quienes consideramos la lectura de los diarios como la oración de la mañana del ciudadano moderno:

Con relación a la explosión de Internet, de la supremacía futura de lo que Umberto Eco denomina las redes telemáticas, nos dice que al menos por largos años estas seguirán siendo un instrumento para una elite culta y joven, no para el ama de casa católica, no para el marginado, el jubilado o la señora burguesa.

"Por ahora, la red telemática puede darles el poder no a ustedes y a sus electores tradicionales sino a mis estudiantes, que establecerán un puente privilegiado con los yuppies de Wall Street".

Y agrega que "no hay que dar por descontado que estas redes puedan seguir siendo acéfalas, eludiendo todo control desde arriba; ya estamos en situaciones de atasco advierte y mañana un Gran Hermano podría controlar los canales de acceso..."

Finalmente nos dice que "la inmensidad de información que estas redes permiten podría llevar a una censura por exceso. El exceso de información lleva o a criterios casuales de selección, o a elecciones atentas permitidas, una vez más, a una elite educadísima."

En síntesis, lo que para Ramonet es la tiranía de la comunicación, para Eco en defensa de la prensa escrita es la necesidad de que ella deje de mirarse el ombligo y deje de buscar la noticia en los poderes tradicionales para asumir de una vez que hay millones y millones de personas que son fuente de noticia, que hay millares de conciudadanos que día a día están construyendo algo, y de cuyo crecimiento o crisis depende el futuro de nuestra sociedad.

Sin duda se trata de la gente, de las mujeres y hombres que habitan nuestro planeta y que en definitiva son los más genuinos exponentes del sentido supremo que tiene el periodismo, en tanto público, democrático, crítico e irreductiblemente independiente de todo lo que huela a poder.

1 HUIDOBRO, Vicente, "Manifiesto patriótico", en BRUNNER, José Joaquín y CATALÁN, Calos: "Cinco estudios sobre sociedad y cultura". Ediciones Flacso $1989 .$.

2 HUMAN RIGHTS WATCH, "Los límites de la tolerancia. Libertad de expresión y debate público en Chile". LOM Ediciones. Santiago de Chile. Noviembre de 1998.

3 LAGOS, Claudia, OTANO, Rafael y SUNKEL, Guillermo. "Dolores y sombras del periodismo chileno". Revista Rocinante No (Fecha ) Santiago de Chile,

4 BLANCO, Guillermo, "El joder y la gloria". Edit. Planeta. Santiago de Chile, 1997. 